\title{
Kidney Rhabdomyosarcoma
}

National Cancer Institute

\section{Source}

National Cancer Institute. Kidney Rhabdomyosarcoma. NCI Thesaurus. Code C159206.

An extremely rare rhabdomyosarcoma arising from the kidney. Most cases are of embryonal type. 